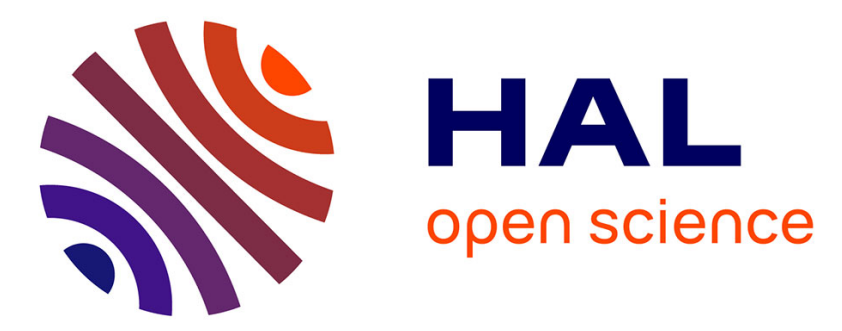

\title{
Visualizing Integration Uncertainty Enhances User's Choice in Multi-Providers Integrated Maps
}

Léonor Ferrer Catala, Franck Favetta, Claire Cunty, Bilal Berjawi, Fabien Duchateau, Maryvonne Miquel, Robert Laurini

\section{- To cite this version:}

Léonor Ferrer Catala, Franck Favetta, Claire Cunty, Bilal Berjawi, Fabien Duchateau, et al.. Visualizing Integration Uncertainty Enhances User's Choice in Multi-Providers Integrated Maps. International Working Conference on Advanced Visual Interfaces (AVI 2016), Jun 2016, Bari, Italy. pp.298-299, $10.1145 / 2909132.2926075$. hal-01258627v2

HAL Id: hal-01258627

https://hal.science/hal-01258627v2

Submitted on 14 Jul 2016

HAL is a multi-disciplinary open access archive for the deposit and dissemination of scientific research documents, whether they are published or not. The documents may come from teaching and research institutions in France or abroad, or from public or private research centers.
L'archive ouverte pluridisciplinaire HAL, est destinée au dépôt et à la diffusion de documents scientifiques de niveau recherche, publiés ou non, émanant des établissements d'enseignement et de recherche français ou étrangers, des laboratoires publics ou privés. 


\section{Visualizing Integration Uncertainty Enhances User's Choice in Multi-Providers Integrated Maps}

\author{
Léonor Ferrer Catala \\ EMS, EA 3082 \\ Université de Lyon \\ Université Lumière Lyon2 \\ Lyon, France \\ leonor.ferrer-catala@univ- \\ lyon2.fr \\ Bilal Berjawi \\ LIRIS UMR5205 \\ Université de Lyon \\ Insa-Lyon \\ Lyon, France \\ bilal.berjawi@liris.cnrs.fr
}

\author{
Franck Favetta \\ LIRIS UMR5205 \\ Université de Lyon \\ Université Claude Bernard Lyon1 \\ Lyon, France \\ franck.favetta@liris.cnrs.fr
}

Fabien Duchateau

LIRIS UMR5205

Université de Lyon

Université Claude Bernard Lyon1

Lyon, France

fabien.duchateau@liris.cnrs.fr
Robert Laurini
LIRIS UMR5205
Université de Lyon
Insa-Lyon
Lyon, France

\author{
Claire Cunty
UMR EVS-IRG
Université de Lyon
Université Lumière Lyon2
Lyon, France
claire.cunty@univ-Iyon2.fr \\ Claire Cunty
UMR EVS-IRG
Université de Lyon
Université Lumière Lyon2
Lyon, France
claire.cunty@univ-Iyon2.fr \\ Claire Cunty
UMR EVS-IRG
Université de Lyon
Université Lumière Lyon2
Lyon, France
claire.cunty@univ-Iyon2.fr \\ Claire Cunty
UMR EVS-IRG
Université de Lyon
Université Lumière Lyon2
Lyon, France
claire.cunty@univ-Iyon2.fr \\ Claire Cunty
UMR EVS-IRG
Université de Lyon
Université Lumière Lyon2
Lyon, France
claire.cunty@univ-Iyon2.fr \\ Claire Cunty
UMR EVS-IRG
Université de Lyon
Université Lumière Lyon2
Lyon, France
claire.cunty@univ-Iyon2.fr
}

Maryvonne Miquel

LIRIS UMR5205

Université de Lyon

Insa-Lyon

Lyon, France

ne.miquel@liris.cnrs.fr

robert.laurini@liris.cnrs.fr

\begin{abstract}
This poster presents an experiment to assess how representation of uncertainty of cartographic integration of multi-providers services is used by end-users ${ }^{1}$.
\end{abstract}

\section{CCS Concepts}

-Information systems $\rightarrow$ Uncertainty $\bullet$ Information systems $\rightarrow$ Location based services $\cdot$ Human-centered computing $\rightarrow$ Geographic visualization

\section{Keywords}

Uncertainty Visualization; Spatial Integration; Spatial Entity Matching; Geographic Information Systems; Interface for e-Tourism

In the domain of tourism, cartographic services such as Google Maps, Microsoft Bing, Nokia Here, OpenStreetMap, provide tourists with a way to find points of interest (POI) such as monuments, museums, hotels, restaurants, which are described with spatial (location) and terminological (e.g., type of POI, phone, price, opening hours, etc.) properties. As the same POI from several providers may reveal inconsistencies, errors and differences, current solutions consist in merging POIs from several providers into one unified map with higher quality $[1,3]$.

Permission to make digital or hard copies of all or part of this work for personal or classroom use is granted without fee provided that copies are not made or distributed for profit or commercial advantage and that copies bear this notice and the full citation on the first page. To copy otherwise, or republish, to post on servers or to redistribute to lists, requires prior specific permission and/or a fee.

AVI'16, June 7-10, 2016, Bari, Italy.

(C) 2016 ACM 1-58113-000-0/00/0010 _..\$15.00.

DOI: http://dx.doi.org/10.1145/12345.67890
When data of sources are different, the merging process may be uncertain (not confident). Our study is based on our previous work [1] where the merging process outputs a three-level confidence scale : lowly confident, averagely confident, or highly confident. In this work, based upon recommendations of MacEachrent et al. [2], we selected the most efficient icons to portray spatial, terminological and global (spatial and terminological) integration uncertainty. We also identified the recommendation to primarily visualize global integration uncertainty on the icons of the merged POIs, and to pop up on demand information about source POIs from the providers. An illustration of the solution is shown in Figure 1. By clicking on POIs' icons, the user can switch to a mode called "source" mode: all source POIs of the source providers (used to calculate the integrated POI) are portrayed as well as all their source properties. However, one crucial assumption still remains to be checked: is portraying uncertainty useful information for tourists? While looking for POIs through cartographic services, how uncertainty portrayal impacts tourists' behavior? This key question became the goal of a new experiment which is the contribution of this poster.

First, we conducted preliminary interviews with professionals in the domain of tourism: tourist offices of Lyon city, SaintEtienne city, and Rhône-Alpes Region in France. We elaborated an online form ${ }^{2}$ to identify relevant contexts and scenarios, that have been performed by 394 potential users. We identified the most frequently used cartographic services between Google Maps, Mappy, Viamichelin, Mapquest, OpenStreetMap, Géoportail, Bing Maps, and Nokia Here. Google Maps came in first position

\footnotetext{
${ }^{1}$ This work was supported by the LABEX IMU (ANR-10-LABX0088) of Université de Lyon, within the program "Investissements d'Avenir" (ANR-11-IDEX-0007) operated by the French National Research Agency (ANR)

${ }^{2}$ https://sites.google.com/site/unimapuvform (in French)
} 


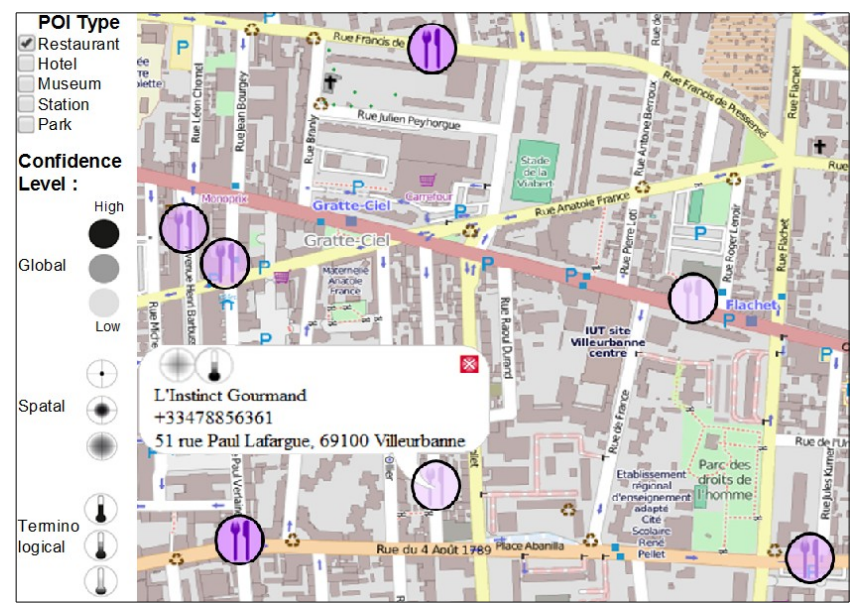

Figure 1. Integration of POIs from several provider: a solution to portray spatial, terminological and global integration uncertainty [1].

$(83.3 \%)$. We observed that in a context of trip planning as well as in the context of on site searching for POIs: price and users' comments are the most important criteria when looking for restaurants or accommodation, and opening hours and price are the most important criteria when looking for a POI with an activity (e.g., a museum).

Then, we implemented a prototype to simulate a cartographic service in two contexts: planning a tourist trip, and on site looking for POIs. New testers were divided into three groups: a first group using a cartographic service with no uncertainty information (control group, $\mathrm{G} 1, N=15$ ), a second group with POIs having the same uncertainty information for all POIs $(\mathrm{G} 2, N=15)$, and a third group with varying levels of uncertainty information $(\mathrm{G} 3, N=15)$. We simulated three missions: 1) testers were asked to imagine they wanted to plan their next holiday trip in Bucharest, and to find an hotel, 2) testers had to find a restaurant (Figure 2), 3) testers had to find a monument to visit. Prices and opening hours ranges had three levels (high/wide, average, low/narrow). We built maps portraying nine POIs which are the combination of the three prices/opening hours and the three confidence levels. We measured the response times (Figure 3).

We can observe that adding "source" providers information increases user's cognitive load $(\mathrm{G} 2>\mathrm{G} 1)$ but this cognitive overload seems to be reduced by visualizing varying confidence levels $(\mathrm{G} 1<\mathrm{G} 3<\mathrm{G} 2)$. We conclude that adding varying uncertainty visualization impacts user's choices and time to make them.

The three missions' objectives were not imposing the utilization of such information but users used it as a major criterion for their choices. Whatever the mission, almost $100 \%$ of G3 testers said they utilized the highest confidence level as the criterion for their choice. We conclude that uncertainty information is taken into account in user's decision.

We globally conclude that visualizing uncertainty is a useful additional feature for potential users, to design cartographic services which integrate POIs from different providers in the context of tourism.

\section{REFERENCES}

[1] Berjawi B., Chesneau E., Seccia G., Duchateau F., Favetta F., Cunty C., Miquel M., \& Laurini R. 2014. Uncertainty Visualization of Multi-Providers Cartographic Integration. In

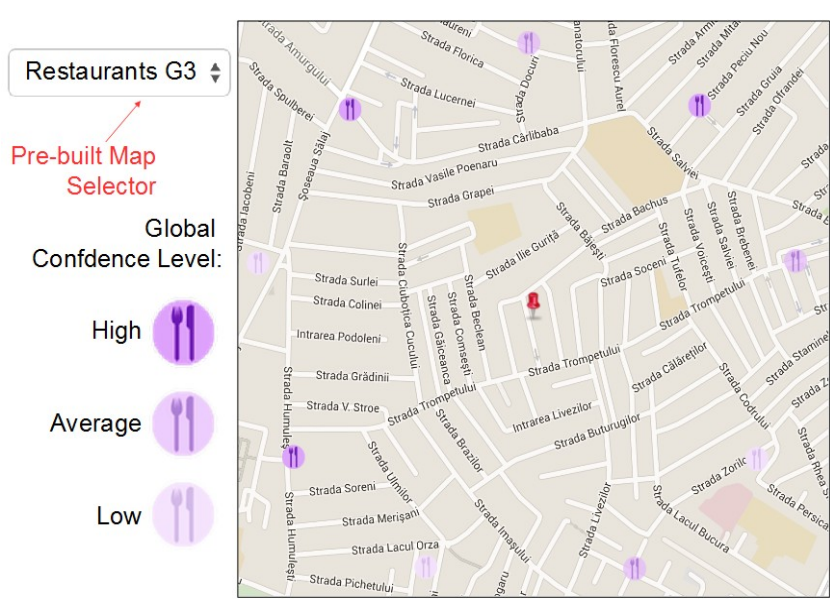

Figure 2. New experiment. In mission 2, testers (in the middle) had to choose a restaurant between nine surrounding ones at the same distance. In this example for G3 testers only, icons indicate different confidence levels. Note that icons looked more contrasted on a screen.
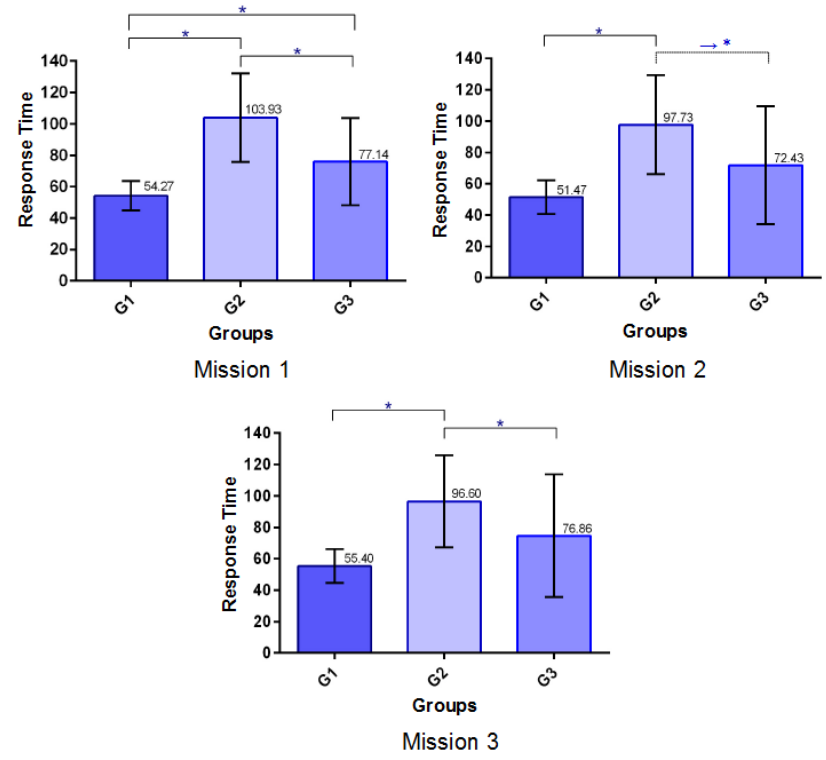

Figure 3. Mean response times for the three missions. Black bars represent standard deviations. "*" indicates significant differences between groups, and " $\rightarrow *$ " a trend towards significance $(p$-value $=.0569)$.

Journal of Visual Languages and Computing, 25, 6, 9951002. Elsevier. JVLC.

[2] MacEachren, A. M., Roth, R. E., O’Brien, J., Li, B., Swingley, D., \& Gahegan, M. 2012. Visual Semiotics \& Uncertainty Visualization: An Empirical Study. IEEE Transactions on Visualization and Computer Graphics, 18, 12, 2496-2505. DOI= 10.1109/TVCG.2012.279

[3] Safra, E., Kanza, Y., Sagiv, Y., Beeri, C., and Doytsher, Y. 2010. Location-Based Algorithms for Finding Sets of Corresponding Objects Over Several Geo-Spatial Data Sets. International Journal of Geographical Information Science, 24, 1, 69-106. 